\title{
Problems connected with evaluation of the process of planned regional development ${ }^{1}$
}

\author{
D. B. W. M. van Dusseldorp and B. E. J. C. Lekanne dit Deprez
}

Received 27 May 1969

\section{Summary}

Evaluation has to be considered as an integral part of the process of planned regional development. It provides the information about the preceding activities necessary to facilitate the steering of future development activities. Evaluation relates to both effects and causes of past developments, and is to be distinguished into several types according to the period in which it is carried out and to the organization responsible for this task. Organizational and socio-psychological aspects of evaluation are discussed in brief.

Problems connected with evaluation of the process of planned regional development are manifold. First the area of research covered by evaluation has to be delimitated in clear terms with respect to the national and local level. Further is pointed at the changing foci of evaluation and the different problems it has to face concomitant with the various activities forming part of planned regional development. Finally some of the most pressing methodological problems are analysed, viz the measurability of results, the determination of planned and autonomous results, the assignment of effects to specific actions, the implications of the length of the plan period.

The authors break a lance for more attention to the methodology of evaluation and wider publication of research reports and studies in this field.

\section{Introduction}

Our growing knowledge of our environment, of our society and of ourselves is making it steadily more possible for us to shape our own future. Planning, a typically human characteristic, is as old as mankind itself, but it has never been applied either so systematically or on such a grand scale as now. Fully realizing that we are living in a dynamic society, we seek not only to foster various aspects of development but also to guide the development of society as a whole towards a specific goal.

Many activities are involved in a development process of this kind. They include precise formulation of the goals and objectives 2 to be achieved, and inventorization and research for a sounder grasp of the existing situation and its development potential. Once ascertained, the existing situation then serves as a basis for a plan incorporating details of the action programme, including allocation of the limited resources available, which will need to be followed if the desired goals are to be achieved. On its acceptance, the task of implementing the plan, which in theory must lead to the desired

1 This article was partly inspired by the authors' participation in a working party on evaluation of Netherlands assistance to development countries led by Professor L. H. Janssen S.J., Tilburg, and in an interdisciplinary working party on regional development planning at Wageningen.

A goal is the general direction in which an enterprise may seek to move. An objective, however, is a concrete milestone in the direction of the goal (Basi, 1968, p. 37). 
result, can be undertaken. Experience has shown, however, that only in a few cases are the goals and objectives ever fully realized, and even then it is usually as a result of repeated amendments and adjustments to the original plan.

Planning is a steering method used in an attempt to lead what is generally an intricate development process in a predetermined direction. It can only be effective provided the effects of the preceding activities have been ascertained in time. A feedback system is an indispensable part of planned development.

The activities required to obtain the information needed for this feedback are deseribed by the term evaluation. Though in theory the importance of evaluation has long been appreciated, and it always takes place in one way or another, its practical application leaves much to be desired. This need cause no surprise in view of the problems confronting evaluation research. This article is an attempt to outline some of the problems in connection with evaluation of the generally complicated development which it is attempted to control by means of governmental planning.

\section{The content of evaluation}

Evaluation may be defined as an inquiry into the factors which have contributed to the success or failure of planned development. ${ }^{3}$

Evaluation research is the study of:

a. The results of planning and its implementation as viewed against its basic goals, and the costs of the planned development;

b. The causes of the success or failure of planning and its implementation, with special attention to the choice of means and the way in which those means have been employed.

Evaluation may confirm that the planning and implementation were carried out in accordance with expectation or it may show that the set objectives have been achieved only partially or not at all. In the latter case necessary data should be given for the amendments or complete replanning required and the way in which this can best be carried out.

\section{Types of evaluation and their interrelationship}

There are various types of evaluation. Depending on the period in which it is carried out, reference may be made to:

a. Interim evaluation, carried out in the course of the planning or its implementation;

b. Final evaluation (ex post), carried out after implementation of the plan.

A distinction may be made between two further types of evaluation, depending on the organization responsible for the evaluation:

a. Internal evaluation, carried out by organizations responsible for planning and implementation and consisting of a critical assessment of their own internal reports on the progress of their work;

b. External evaluation, carried out by organizations working independently but in

3 In the literature and in international terminology the term 'evaluation' is often used in the sense of an advance appraisal $(e x$ ante) of the possibilities offered by a specific type of development. In this article the word is used exclusively in the sense of an analysis of effects occurring after planning activities. 
close collaboration with the organization responsible for planning or implementation.

Interim evaluation is in many cases carried out by the organizations responsible for planning and its implementation.

Internal reports are drawn up for practically all activities of any magnitude. Though such reports need not necessarily take the form of scientific evaluation they almost always result in adjustments in the planning or its implementation.

Internal evaluation and interim evaluation thus coincide. In general, however, it is not ideal for all interim evaluation to be carried out by the relevant organizations themselves.

Final evaluation and external evaluation are also often found to coincide. The former is usually entrusted to an organization which is not directly concerned with the planning or its execution.

Planning activities may be evaluated from the perspective of effects, i.e. what is the (ultimate) influence with reference to the goals and objectives, or of the effectiveness, focussing rather on the operations of planning and implementation (Wright, 1955, p. 418) 4. A thorough final evaluation of effects is only feasable as a rule when interim evaluation has taken place, or at any rate when adequate internal reports have been compiled on the progress booked to date. Evaluation of effectiveness forms part of interim as well as final evaluation.

\section{Organizational and socio-psychological aspects of evaluation}

If an assessment is to be objective, it is important that it be made by a neutral organization, particularly in view of the fact that the organizations connected with the development in question will themselves be scrutinized and assessed. Obviously, those who are concerned with the compilation or implementation of a plan will not be altogether objective as regards the results of that plan. Their involvement in their own work is so close that they can hardly view it objectively. If evaluation were to be left to the organization entrusted with the plan's execution, there would be a risk of any lack of result being attributed too readily to the quality of the planning. If, on the other hand, it were to be carried out by the planning organization, too much emphasis could be placed on the problems attending implementation. Moreover, regardless of whether the evaluation is favourable or unfavourable, it can have far-reaching consequences for the organizations concerned, affecting the means made available to them as well as their structure and working methods. It is therefore preferable that a neutral organization undertake the final evaluation and, wherever possible, the interim evaluation at set periods so that the objectivity of the findings can be beyond doubt. Making use of the services of a neutral organization is also accompanied by a number of problems. If an evaluation is really to succeed, all data required for that evaluation will have to be supplied. This means that the two organizations, the one carrying out the evaluation and the one being evaluated, will have to work in close collaboration and in complete openness with each other, which will require a sound mutual understanding and endowment of the evaluating organization with wide powers. Evaluating organizations are sometimes regarded with suspicion, especially by execu-

- Wright distinguishes also a third perspective of efficiency: do the results warrant the money and effort spent. The present article deals solely with problems in the evaluation of effects and effectiveness. 
tive bodies since in the past projects were evaluated only when there were indications that the objectives could not be attained by the plans being implemented. It was then reasonable enough to predict in many cases that the findings of the investigation would not be very favourable to the organizations concerned.

It often happens that the more comprchensive type of evaluation is decided upon only when the execution of a plan is well under way. This docs not mean, however, that the implementation should be the sole object of systematic assessment. Certain imperfections in the implementation or some negative effects can often be traced back to mistakes made during the preceding stages. Some of those mistakes could have been picked up and rectified if systematic evaluation had been introduced in those carlier stages. This is an argument in favour of evaluation as a permanent part of the entire process of planned development.

In view of the fact, however, that planning is directed toward a future situation, incorrect decisions and methods will not always be recognized as such during the initial stages of planned development. As far as the evaluation of the effects is concerned the total result can only be assessed during the implementation, and more particularly after it has been in progress for some time. The evaluation of the effectiveness, however, can start at once.

A further source of difficulty is the fact that evaluating organizations tend to devote much attention in their reports to those parts of the project which have not worked out very well, and to take for granted and make little mention of all more successful activities. This approach creates an unfavourable impression of the evaluated organization's activities as a whole.

In view of the many thorny problems connected with evaluation, close consideration ought to be given to the staff to be entrusted with the work of evaluation, which must be selected with particular care, as well as to the relationship between the evaluating organization and the organization to be evaluated.

Evaluation should thus be a permanent activity and not one restricted to stages or parts of a project which are endangering or threatening to endanger the progress planned. Moreover, by devoting attention to all activities connected with the process of planned development, many of the negative aspects often apparent in present-day evaluation research can be avoided.

For evaluation to be effective, all organizations connected with the development concerned should carry out internal and interim evaluations. It is further to be recommended that organizations of a sufficient size set up their own small evaluation units to make critical assessments of internal progress reports and to pass on their findings to all concerned.

The organizational structure ultimately chosen will depend on the circumstances. The important point is that external evaluation should be entrusted to an organization which is regarded as neutral and capable by all parties concerned.

\section{Problems connected with evaluation in the context of planned regional development}

The problems encountered in connection with evaluation vary according to the nature of the development project and the type of planned development concerned. Evaluation of a project or action programme of limited magnitude gives rise to problems different from those encountered in assessment of the planned development of a region or country. Evaluation research in the context of planned regional development serves to illustrate this point. 
The main characteristics of a regional plan are (van Dusseldorp, 1967, p. 206) :

1. It indicates the contribution of the regional plan to the national development.

2. The action programme lists all local (component) plans of importance for regional development, giving their interrelations as well.

3. It gives only a general framework for regional development that requires further elaboration before it can be carried into effect.

The main activity during the implementation of a regional plan is the co-ordination of all research, planning and implementation as far as the local plans and regional policies are concerned.

Evaluation of large-scale planned development is still comparatively new, as is obvious from the limited conceptual apparatus and the often primitive research methods available for evaluation. It is not the intention to introduce new evaluation research methods in this article, but to deal briefly with a number of the problems occurring in connection with planned regional development. They refer to:

1. Delimitation of the area to be covered by evaluation;

2. Evaluation of the various activities forming part of planned regional development;

3. Some methodological problems.

Some of the problems discussed are of a more general nature, for they also occur in evaluation of other kinds of planned development, though perhaps in a different way and to a different extent.

\section{Delimitation of the area to be covered by evaluation}

A distinction should be made between a) evaluation of planned regional development, and b) evaluation of planned development at national or local level.

Evaluation at regional level does not include ascertaining the extent to which regional development fits into the national framework. This is one of the functions of evaluation of planned national development. The problem of defining the area to be covered by evaluation at national and regional level is especially evident in evaluation of the way in which the goals and objectives of a regional plan were developed.

Planned regional development proceeds from all developments arising from the realization of component (local) plans. The sum total of the objectives of these plans forms the goal set for the regional plan. If it is necessary to ascertain why the aims of the regional plan have not been attained, this will involve evaluation of all its component plans. This means that evaluation of regional development can only get under way once the results of the interim and final evaluations of the component plans executed in the period to be evaluated have become known. In other words, evaluation of the component plans must have reached an advanced stage before evaluation of the effects at regional level can profitably be undertaken. With the evaluation of the effectiveness of the implementation c.q. the quality of the co-ordination of the research, planning and implementation activities as far as the component plans are concerned can be started at once.

\section{Evaluation of the activities forming part of planned regional development}

For the sake of clarity the planning activities referred to below are taken to be timedelimited units. It should be noted, however, that these activities, once started, in fact 
continue non-stop and are thus simultaneous, a factor which actually has a complicating effect on evaluation.

\section{Goals and objectives}

The objectives should be measurable. If, for instance, the objective is to obtain a certain level of living, it must be defined in clear, measurable terms. Many objectives in the social sector (literacy, for example, or educational levels) are much more difficult to measure than might at first seem to be the case.

In many regional plans the objectives are not clearly formulated. In cases of this kind the evaluating organization will have to arrive at a precise definition of all objectives envisaged when planned development was set in motion.

A problem which sometimes occurs in the analysis of objectives is one whereby the objective formulated by the authorities and forming a clearly-defined part of the plan (explicit objectives) are accompanied by others based on conscious or unconscious desires which are not openly referred to but which nevertheless play an important part in the design and implementation of the plan (implicit objectives). An objective of this kind in forcign development aid, for example, might be the promotion of one's own trading interests; and in regional planning, promotion of the interests of specific groups. Where this is found to occur, the evaluating organization will have to distinguish between implicit and explicit objectives and determine the influence of the former.

The primary goals, i.e. the goals set by the politically responsible section of the government and included in the plan, should be regarded for the purposes of evaluation as given.

The derivate objectives, i.e. the objectives obtained through a further elaboration by the administrative machinery of the primary goals and included as such in the plan, should be subjected to evaluation as should also the way in which they have been developed. The next step is then to determine whether the sum total of derivate objectives amount to the given primary goals and to ascertain the extent to which they are geared to one another. With planned regional development it is generally the intention to attain a number of primary goals and a large number of derivate objectives. Some objectives may be competitive. To give an example, it is not always possible to combine rapid economic growth with efforts to achieve a wide distribution of the national income, for instance by devoting a large part of the available funds to a comprehensive social welfare programme.

A critical analysis will have to be made of the entire process of fixing and interadapting the objectives of planned regional development.

In order to prevent resistance on the part of the organizations to be evaluated, it is of considerable importance that the evaluation area be clearly defined beforehand, particularly as regards the objectives of the planned development. This point needs stressing because there is often a lack of sufficient data on the goals and objectives and the way in which they were developed. As a result, this part of the research may demand a great deal of time and may touch on fringe areas of the existing policies. Examination of the objectives derives its importance from the fact that they constitute the true evaluation criteria.

\section{Inventorization and research}

It will need to be determined in the course of evaluation whether in view of the funds available for inventorization and research all data required for analysis of the existing situation have been collected. This means ascertaining whether the data as- 
sembled are adequate both quantitatively and qualitatively and whether many of them are in fact not extraneous to the analysis of the existing situation. A further important point is whether the correct and most efficient inventorization and research methods have been employed. The way in which the collected material is presented will also have to be subjected to scrutiny. The development potential of the region concerned should be clearly indicated in the presentation, as should also all existing impediments to the realization of that potential.

\section{Design of the plan}

It will have to be ascertained whether in designing the plan:

1. efficient work methods were employed;

2. all particulars about the existing situation were taken fully and properly into account, and were presented in such a way that they can be used as a baseline for the evaluation;

3. the action programmes were consistent both individually and collectively;

4. the action programmes were adapted to the capacities of the executive machinery in its final form after the introduction of any amendments proposed, and attention was given to the place of internal and external evaluation in the structure of the administration.

\section{Implementation}

In evaluating the implementation of regional development plants attention should specifically be devoted to determining the extent to which co-ordination of the component plans contributed to the under- or over-attainment of the fixed objectives. This will also involve determining whether the formulation of the objectives of the component plans was such as to have contributed in the right way to the regional objectives.

\section{Methodological problems}

\section{Measurability of the results}

The effects of a regional plan and the requisite investment in its broadest sense cannot always be expressed in figures.

For a sound evaluation it is moreover of importance that a large number of data on the situation forming the point of departure for the development plans, i.e. baseline data, be available. Analysis of the existing situation should be carried out in a way permitting it to be set out in clearly measurable components.

\section{Autonomous and planned development}

Planned regional development is always the guidance or stimulation of an existing process of change, whether or not influenced by planning activities carried out in the past. The original situation may also be expected to change without planned intervention. The extent and course of such autonomous development will have to be ascertained before it can be decided to what degree any given regional development is the direct result of the regional plan. This will not give rise to any special difficulty in a large-scale irrigation project in a desert area, but in many instances sizeable problems are encountered in efforts to determine the extent and course of autonomous development. Its influence can only be traced when the assumed external condition taken by the planners as their point of departure is clearly indicated in the plan. The possibility and benefit of the use of a 'control situation', in this case comparison with the devel- 
opment of an identical region where no planning action has been taken, is strictly limited. It will also be necessary to discover how far events have taken place during the plan period which were not provided for in the plan, and the extent of their influence on the regional development.

Here, too, measurement problems of considerable magnitude are encountered, even when they relate to clearly discernible phenomena such as natural disasters or falling prices for certain products. The positive or negative influence of the sudden occurrence of certain social phenomena like the emergence of a charismatic leader is practically unmeasurable. Improvements to the existing measuring techniques, particularly those employed by the social disciplines, would greatly benefit evaluation methods. Properly planned regional development is always the result of comprehensive planning and implementation. This being so, evaluation should be equally comprehensive, i.e. it entails determining whether the optimal relationship between the physical, economic and social aspects of planning and its implementation has consistently been attained. Evaluation of regional development must for this reason always be interdisciplinary. Many of the evaluation studies carried out over the past decades have dealt only with one of the aspects (technical, economic or social) to which the success or failure of a plan and its implementation were attributable. As more and more the failure of projects is attributed to social factors and as the social disciplines in particular are displaying an interest in evaluation there is danger of too great an emphasis being placed on the social aspect.

In selecting the members of an evaluation team it should constantly be borne in mind that the team must be capable of assessing the comprehensiveness of both planning and implementation.

\section{Assignment of effects}

The problem of appraising autonomous development is in fact part of the problem of assigning the effects which accompanies the whole process of planned development. For the essential point of planned development is its comprehensive integrated approach. One is thus continually confronted with the question of how the effects are to be attributed to the action programmes provided for in the regional plan and to the different parts of each programme (physical, economic and social). A further question is the extent to which certain effects should be ascribed to the implementation or to the preparatory stages of each programme. Moreover, each separate programme generally contributes to more than one of the fixed objectives, thus giving rise to the additional problem of weighing the objectives one against the other.

\section{Length of the plan period}

A further problem connected with the evaluation of regional planning is the length of time involved, which may be anything up to 10 or 20 years, or even more. This makes interim evaluation urgently necessary, which means in turn that there must also be interim objectives. It will also be necessary to indicate how the action programmes are distributed over the periods in which the interim objectives are to be attained. The omission of this point from many regional plans hinders interim cvaluation.

\section{Conclusion}

Thus evaluation of regional development bring many problems. Many questions relating to the methods to be used still remain to be solved. 
Evaluation is nevertheless an essential part of planned development, for no development can be steered effectively without feedback. It is therefore of cardinal importance that all disciplines concerned with planning, implementation and evaluation give attention to the development of effective methods, and particularly to measuring the results of plans carried into action. This constitutes a special challenge to the socioeconomic disciplines.

In view of the problems accompanying all evaluation research it is essential that the results and the way in which they have been obtained be made available to colleagues for their critical appraisal. Results of evaluation research, usually containing critical comments, often get no further than internal reports. It is important, however, that they be made public. In addition, evaluation reports must devote sufficient space to details of the procedures and methods followed and to the difficulties encountered in the course of the work. Only then can the knowledge essential for the growth of evaluation into a science be gained quickly.

Though for the present evaluation has to be carried out under circumstances and with methods which are far from ideal, its role in the process of planned regional development is nevertheless an essential one.

\section{References}

Basi, R. S., 1968. Action Administration, Asia Publishing House, London.

Dusseldorp, D. B. W. M. van, 1967. Meerdimensionale overheidsplanning (Multidimensional governmental planning). Veenman, Wageningen.

Evaluation techniques, 1955. Int. soc. Sci. Bull. 7 (3): 345-458.

Wright, C. R., 1955. Evaluating mass media campaigns. Int. soc. Sci. Bull. 7 (3): 417-430. 